\title{
DETERMINATION OF THE FOREST ROAD NETWORK INFLUENCE ON THE SUPPLY CHAIN FOR FIREWOOD PRODUCTION BY DISCRETE EVENT SIMULATION
}

\author{
Raffaele Cavalli, Stefano Grigolato, Marco Pellegrini
}

\section{Introduction}

Simulation is the process of building a model of a real or proposed system to study the performance of the system under specific conditions. A simulation model could be classified as being static or dynamic, deterministic or stochastic and discrete or continuous [Bank 2005].

In the last decade, in several studies concerning forest operations, dynamic, stochastic and discrete simulations have been applied [Asikainen 1998; Wang 2003; Väätäinen 2010; Asikainen 2010a; Hogg 2010]. Dynamic because the effects of changing variables and the workflow of the system according to the simulation time are analyzed, stochastic because randomness of observation is considered; discrete because the state variable changes only at a discrete set of point in time. These types of simulations are generally called discrete event simulations [D-es] and are generally applied to analyze the behavior of a system defined as a collection of entities, usually workers and machines, that act and interact toward the accomplishment of some logical end over time [Law 1991].

Asikainen [1995] and Ziesak [2003] report some advantages of the D-es simulation techniques, one of which is the capability of this application to analyze discrete and complex real-world situations that cannot be solved by analytical operational methods because of various interactions between the system components. In addition the approach of D-es permits to describe the interactions between the system elements and model the effects of random processes.

At a tactical level, many D-es models were developed for the analysis of the efficiency in transport interactions. The logistic of a chipping terminal was also modeled by a D-es model, which was based on a manufacturing simulator in order to compare different

Paper received 08.09.2011; accepted 23.10.2011

Raffaele Cavalli, Stefano Grigolato, Marco Pellegrini, Forest Operations Management Unit, Dept. Land, Environment, Agriculture and Forestry, University of Padova. E-mail: stefano.grigolato@ unipd.it. Tel. 0039.0498272701, fax 0039.0498272774 loading and transport technologies [Asikainen 1998]. In this study chipping into truck, chipping onto ground and loading using a wheeled loader, long-distance transport by truck with drawbar trailer, by truck with semitrailer and by truck with interchangeable platforms were considered.

Väätäinen [2010] investigated through D-es the cost-effective patterns of harwarders for forest machine contractors in different logging structures and conditions. A D-es model was also programmed to find optimal set-ups for the supply chain of crushed material made from stumps at different road transport distances. The simulation model was based on the continuous supply of crushed material from landings to a district heating plant [Asikainen 2010]. Recently, a D-es model was developed to find the optimal setups for the timber yarding-processing-truck transport system in mountainous condition using a logging site and transport distance database as input [Asikainen 2010a].

At an operational level, applications of the D-es model also concern the analysis of interaction to study the cost-efficiency of a single machine or specific operation systems. By changing simulation inputs and observing the result outputs, machine and system behaviors can be studied and compared with different simulation runs. This allows largely deterministic base simulations that can be carried out to illustrate the effects of machine interactions. Also a groundbased timber harvesting system was modeled by an object-oriented model from felling to extraction in order to evaluate the interaction of stands, harvester treatments, machines and extraction patterns [Wang 2003].

Chipping operation systems in thinning were also analyzed by evaluating bin size, chipper productivity, in-field extraction distance and forest-road haulage distance [Talbot 2005], while multi-stem the mechanized harvesting operation was analyzed under the South Africa condition by comparing the current system to two hypothetical systems. One of the alternative systems was based on modifying the operation procedures but by considering the same machines and equipments of the current system, the second one by 
changing also the machine and the equipment [Hogg 2010].

Some of these works have addressed the development of D-es on a single component of a more complex supply chain [Asikainen 1998; Wang 2003; Talbot 2005; Hogg 2010] and only few have analyzed the interaction between more parts on a complex supply chain [Asikainen 2010a; Asikainen 2010b].

The study aims to develop a D-es model for evaluating the productivity of the wood supply chain for firewood production according to the current operational level from the harvesting site to the firewood production terminal. Therefore the D-es model will be applied to evaluate the productivity of the entire supply chain by considering the complexity of the transportation network with the support of the GIS network analysis according to different scenarios.

\section{Materials and methods}

\subsection{Study site}

The study concerns a firewood supply chain located in the in northeastern part of Italy (Cansiglio forest), latitude $N 46^{\circ} 12^{\prime} 37$ - $46^{\circ} 11^{\prime} 67$, longitude $\mathrm{E}$ $12^{\circ} 45^{\prime} 03-12^{\circ} 46^{\prime} 61$.

The forest plot (11.4 ha) consisted in a high stand forest almost exclusively of beech (Fagus sylvatica L.) and sporadic individuals of Norway spruce (Picea abies Karst.). The altitude ranged from $1248 \mathrm{~m}$ to $1398 \mathrm{~m}$ a.s.l. with a slope gradient ranging between 5 and $35 \%$. The average growing stock was $423 \mathrm{~m}^{3} \mathrm{ha}^{-1}$ with a mean rate of growth equal to $7.6 \mathrm{~m}^{3} \mathrm{ha}^{-1}$. The adopted silvicultural system was the shelterwood method and the analyzed operation regards a shelterwood selection cut with a cut mass of $776 \mathrm{~m}^{3}$ on 11.4 ha (exploitation percent about $15 \%$ ). The mean diameter at breast height of the cut trees was $24 \mathrm{~cm}$ and the average height was $22 \mathrm{~m}$.

\subsection{Study layout}

The study evaluates a distinctive supply chain for firewood production. The case study can be considered a representative situation of the application of the full tree system (FTS) for firewood production from broadleaves high stands in medium gentle terrain. The supply chain was identified by four steps (Fig. 1): extraction (Step A), cross-cut operation (Step B), offroad transport (Step C) and on-road transport (Step D).

The study considers the processes and the workflow of the wood from the stump site to the terminal where wood in the form of logs and bundles of $1.1 \mathrm{~m}$ length assortments were cut and split into firewood.

The extraction (Step A) was performed by hauling the felled full trees from the stump to the nearest landings. The extraction operation was ground based and involved one agricultural tractor $(67 \mathrm{~kW})$ with a forest winch. This operation was performed by two operators, one driving the tractor and one preparing and hooking the loads (normally one full tree).

At the landing, four operators cross-cut full trees into logs (4-6 m length and $>20 \mathrm{~cm}$ diameter) and into small assortments of $1.1 \mathrm{~m}$ length considering three different classes of diameter at half length $(<10 \mathrm{~cm}$,

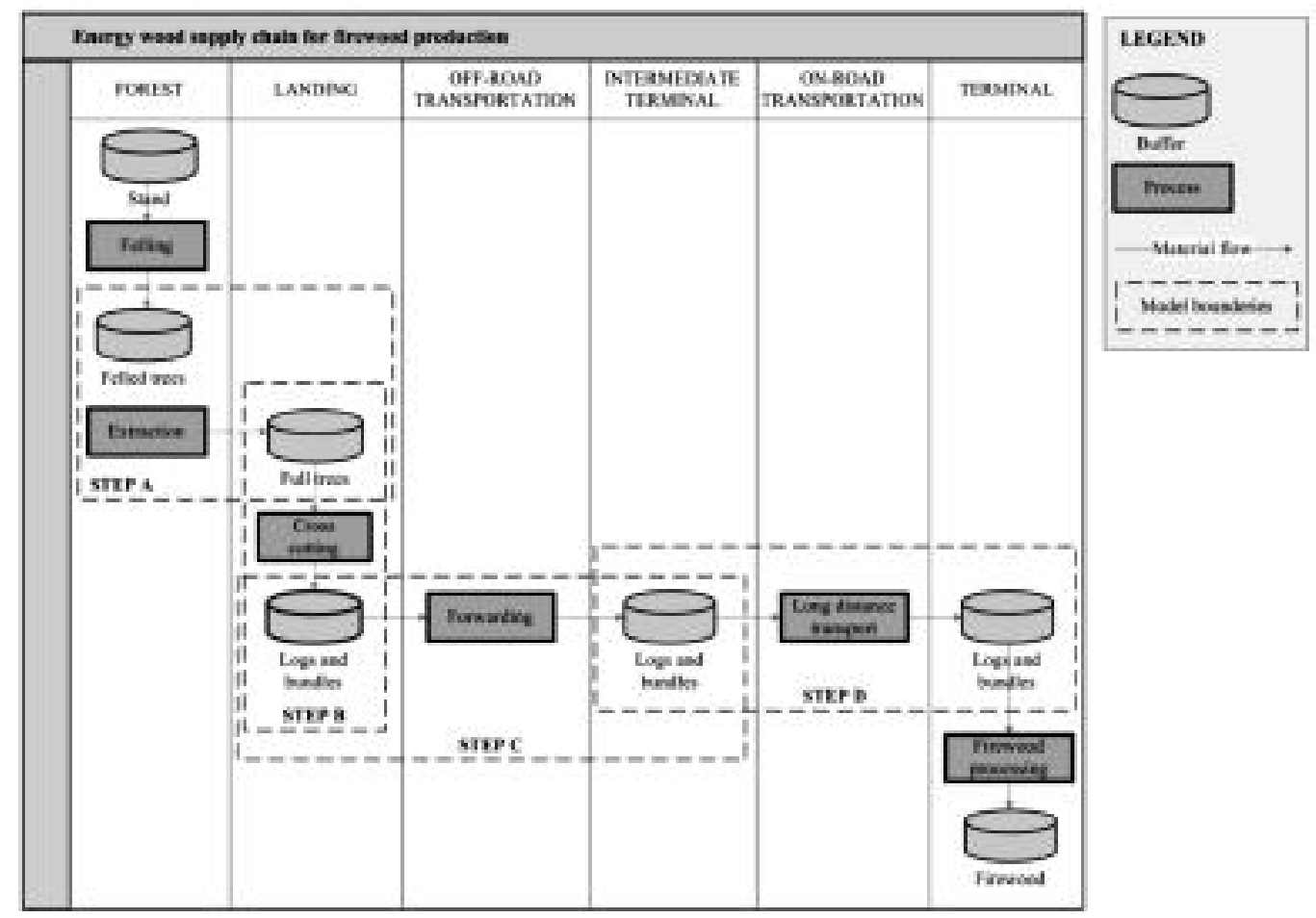

Fig. 1 - Supply chain of full trees for firewood production. 
$10-15 \mathrm{~cm}, 15-20 \mathrm{~cm}$ ) (Step B). One operator was involved in the piling operation of $\log s$ by using a loader (lifting moment $60 \mathrm{kN}$ m and maximum reach of the boom $6.50 \mathrm{~m}$ ) attached to an agricultural tractor $(74 \mathrm{~kW})$, which was located in front of the cross-cutting area. When full trees arrived to the landing, the same operator grappled and moved the unhooked load into the cross-cutting area (landing). At the same time the tractor with the forest winch went back to the stump area for a new extraction cycle. The same operator on the tractor with the crane pilled logs and bundles in piles (maximum 4-4.5 m height), which were located at the right and left side of the same tractor. Other two operators cross-cut the full trees while the remaining operator was mainly busy to sort, according to the diameters at half length $(<10 \mathrm{~cm}, 10-15$ $\mathrm{cm},>15 \mathrm{~cm}$ ), the small assortments into three different frames (one for each diameter) which were then used for assembling the bundles (70 cm diameter).

Logs and bundles were subsequently transported off-roads to the transshipment site along tractor roads by an agricultural tractor $(81 \mathrm{~kW})$ with a trailer with mechanical traction and a payload of $11 \mathrm{t}$ (Step C). Transport on a public road to terminal was performed by a $4 \times 2$ WD truck $(294 \mathrm{~kW})$ and trailer with a total payload of $22 \mathrm{t}$ (Step D).

\subsection{Definition of the D-es model}

The model was developed on the base of Figure 1 to meet the primary objective to evaluate the influence of the extension of a forest road network on the firewood supply chain. The model was developed as a dynamic, stochastic and discrete simulation model (D-es).

The D-es model was created using the Witness simulation modeling software [Lanner 2009], a visual entities-based simulation application for system dynamics models.

The model was therefore constructed interactively in three steps (definition step, detailing step and logic step) via graphic interfaces. According to the workflow of the supply chain, the names and quantities of the elements and the variables of the system were specified at the definition step. The detailing step allowed then to define the parameters of each element such as cycle times, setup times, transport capacities and delay times. The logic step determined then how each element operates and how its operation depends on the action of other elements or state variables.

\subsection{Functions and parameters of the D-es model}

Simulation calls for information about the variables and processes. For instance, production functions for the different working phases of the supply chain needs to be defined. To define the productivity for extraction, cross-cut operation, off-road transportation and on-road transportation time studies were sorted out in May and June 2009 and according to the basic time concepts proposed by Björheden [1991].
Extraction was studied adopting the stop-watch method. Data collection of the main factors affecting time consumption of extraction considered: volume (generally a single tree, $\mathrm{V}, \mathrm{m}^{3}$ ), loaded $(\mathrm{LD}, \mathrm{m}$ ) and unloaded driving (UD, $\mathrm{m}$ ) distance and slope gradient (SL, \%) of the trail. The load volume (V) was determined after the cross-cut process by measuring the diameter at half length and the length of each single log (log volume, LV) and by recording the number and the size of each small assortment (small assortment volume, SAV) according with the frame where they were sorted. The extraction distances and the slope gradients were measured by a laser rangefinder with an integrated compass allowing to measure the straight distance and slope within $400 \mathrm{~m}$. The crosscut operation of full trees at landing was studied with the support of a digital video-camera and the work sampling method. The off-road and on-road transportation was also investigated by adopting the stopwatch method to determine the average speed for loaded and empty travel and for loading and unloading time. In the case of the on-road transportation the distance was always the same.

\subsection{Statistical analysis}

The time and motion study of the ground-based extraction was subdivided in travel loaded TL and in travel unloaded TU. For the travel loaded the productivity hypothesis was $\mathrm{TL}=\mathrm{f}(\mathrm{V}, \mathrm{LD}, \mathrm{SL})$ and for the travel unloaded TU $=\mathrm{f}$ (UD, SL). The time and motion study of the cross-cut (CC) supposed the following productivity hypothesis $\mathrm{CC}=\mathrm{f}\left(\mathrm{V}, \mathrm{V}_{-}\right.$Type $)$, where $V \_t y p e$ corresponds to a factor equal to 1 in the case of a rate of small assortment higher than $10 \%$ on the total volume, otherwise the factor is 0 .

According to Stampfer [2010], the variance analysis was used to quantify the influence of nominal and ordinal-scaled variables. Also the analyses for the three time and motion studies consisted in: estimation of significant effects of the co-variables and factors and an analysis of their significance, the evaluation of the non-linearity of the co-variable, an analysis of the interaction between factors and co-variables, parameter estimation of significant factors and co-variables and regression analysis. Further, the Box-Cox transformations procedure was applied to determine an optimal transformation of the tree volume for stabilizing the variance and making the deviations around the model more normally distributed.

The locking and unlocking time for each cycle time was verified in terms of distribution. The distributions were analyzed by the Kolmogorov-Smirnov test $(\mathrm{K}-\mathrm{S})$ at the confidence interval of 0.05 and supposed to be of the normal type.

Also for the collected data concerning the speeds of the off-road transportation and the on-road transportation and the un-loading and loading time were analyzed by the K-S test at the confidence interval of 0.05 and supposed to be of the normal type. 


\begin{tabular}{|c|c|c|c|c|c|c|c|c|c|c|}
\hline \multirow[b]{3}{*}{$\mathrm{SC}$} & \multirow{3}{*}{$\begin{array}{l}\text { Site } \\
\text { Landing }\end{array}$} & \multirow{2}{*}{\multicolumn{3}{|c|}{$\begin{array}{l}\text { EXTRACTION } \\
\text { NETWORK } \\
\text { distance }\end{array}$}} & \multirow{3}{*}{$\begin{array}{l}\text { Site } \\
\text { Transshipment }\end{array}$} & \multicolumn{3}{|c|}{$\begin{array}{l}\text { FOREST ROAD } \\
\text { NETWORK }\end{array}$} & \multirow{2}{*}{\multicolumn{2}{|c|}{$\begin{array}{l}\text { PUBBLIC ROAD } \\
\text { NETWORK } \\
\text { distance } \\
\end{array}$}} \\
\hline & & & & & & \multirow{2}{*}{$\begin{array}{l}\text { density } \\
\text { Density }\end{array}$} & \multicolumn{2}{|c|}{ distance } & & \\
\hline & & Mean & StDev & Sum & & & Mean & Sum & Mean & Sum \\
\hline - & n. & $m$ & $\mathrm{~m}$ & $\mathrm{~km}$ & n. & $m b^{-1}$ & $\mathrm{~m}$ & $\mathrm{~km}$ & $\mathrm{~km}$ & $\mathrm{~km}$ \\
\hline A & 1 & 230 & 146 & 336 & 1 & 7.73 & 750 & 137 & 31.20 & 1981 \\
\hline$B^{*}$ & 2 & 116 & 60 & 169 & 2 & 14.48 & 968 & 177 & 31.85 & 2022 \\
\hline C & 3 & 79 & 36 & 116 & 2 & 26.14 & 1112 & 203 & 32.11 & 2038 \\
\hline D & 4 & 68 & 30 & 99 & 2 & 38.44 & 1254 & 229 & 31.92 & 2026 \\
\hline E & 5 & 65 & 30 & 95 & 2 & 38.44 & 1277 & 233 & 31.59 & 2005 \\
\hline $\mathbf{F}$ & 6 & 61 & 30 & 89 & 2 & 56.92 & 1314 & 240 & 31.55 & 2003 \\
\hline G & 7 & 58 & 29 & 84 & 2 & 68.16 & 1263 & 230 & 31.73 & 2014 \\
\hline H & 8 & 53 & 26 & 77 & 2 & 68.16 & 1238 & 226 & 31.66 & 2009 \\
\hline
\end{tabular}

TABLE 1 - Scenarios (SC) and main values of the transportation network according to the increment of the forest landings.

Randomly-occurring delays have an important influence on machine and operation performance. The frequency of the time between breakdowns and the breakdown times were also determined. The distributions of breakdown time and interval were studied by the K-S test. All the breakdown distributions were supposed to be of the Erlang type with shape factor $\mathrm{k}$ equal to 2 (bell-shaped distribution, strongly skewed to the left and with a shape similar to lognormal distribution) [Lanner 2009].

\subsection{Model validation}

The D-es model was built according to the investigated situation. During the model construction the logical proceeding of work sequences were tested by running the model step by step and observing the interaction between all the elements by graphic and value outputs.
According to Banks [2005], the validation ensures that the model is a realistic representation of the real system. The simulation model was verified with 15 daily firewood loads unloaded at the terminal, which were registered by the forest enterprise. The validation supposed for the daily average ( 5 working days, $2880 \mathrm{~min}$ ) of unloaded firewood mass in term of logs and small assortments of 15 repetitions with a warmup period of $480 \mathrm{~min}$ and several different sets of random number streams.

\subsection{Experimental design}

The experiment design considered 8 different extensions (scenarios, SC) (Tab. 1) of the transportation network as a result of the increasing number of landings within the forest plot (Fig. 2).

The numbers of the loads (the felled trees) corresponds to the location of the 731 stump sites inside

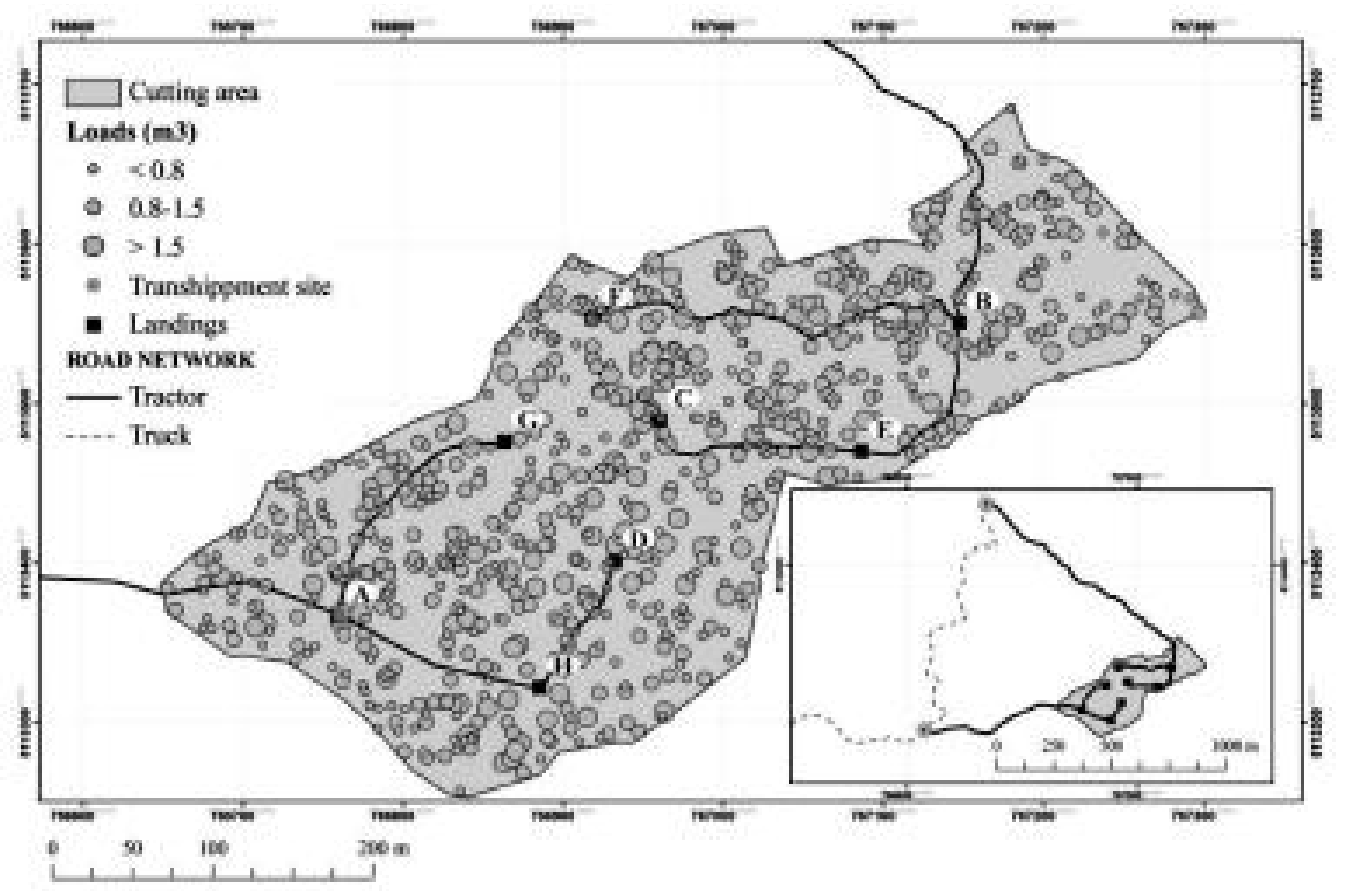

Fig. 2 - Layout of the studied area with the distribution of the loads, the maximum supposed road network extension and the landings location. 


\begin{tabular}{|c|c|c|c|c|c|}
\hline Siep & Descriptixe & Unit & Function/Distribution type & Obs. & $p$-value \\
\hline \multirow[t]{7}{*}{ A } & Unhooking ( $\mathrm{PSH}_{4}$ ) & $\$ 100$ & Nermal $(\mu=46.93$ SD -23.6$)$ & 105 & $0,710(\mathrm{~K}-\mathrm{S})$ \\
\hline & Hooking ( $\left.\mathrm{PSH}_{e}\right)$ & $5 / 100$ & Nermal $\{\mu-327.3$ SD-114) & 105 & $0.471(\mathrm{~K}-5)$ \\
\hline & Travel Unloaded TU (PSH, & $\$ / 100$ & $\mathrm{TU}=33.683+(0.963 \times \mathrm{D})+2.612 \times 5 \mathrm{SL} .\left(\mathrm{k}^{1}=0.72\right)$ & 105 & 0.000 (reg) \\
\hline & Travel Loaded TL. (PSH, & $5 / 100$ & $\left.\mathrm{TL}=-27.379+\left(142.713 \times \mathrm{V}^{2} \mathrm{x}\right)+(1.003 \times \mathrm{DL}) \mathrm{a}^{2}-4.51\right)$ & 105 & 0.002 (reg) \\
\hline & Delays time & $\min 1100$ & Frlang $(\mu-6.115 \mathrm{SD}-4.769)$ & 21 & $0.083(\mathrm{~K}-\mathrm{S})$ \\
\hline & Interval delay time & $\min 160$ & Filang $(\mu=27.58 \mathrm{SD}=7.38)$ & 21 & $0.172(K-S)$ \\
\hline & 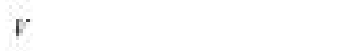 & $m^{3}$ & Normal $(\alpha==1.046 \mathrm{SD}=0.503)$ & 105 & $0,732(\mathrm{~K}-5)$ \\
\hline \multirow[t]{3}{*}{ B } & Cross-cuit ( $\left.\mathrm{PSH}_{3}\right)$ & $\min 100$ & $\mathrm{CC}-0.558+\left(11,084 \times \mathrm{V}^{2 \times}\right)-(3.068 \times \mathrm{V}$ TYPE $)\left(\alpha^{2}-061\right)$ & 53 & $0.006(\mathrm{reg})$ \\
\hline & Delay & $\min 1100$ & Erlang $(\mu-2.111$ SD- 1.278$)$ & 19 & $0.061(\mathrm{~K}-\mathrm{S})$ \\
\hline & Interval delay time & $\min 100$ & Erlang $(\mu-33.211 \mathrm{SD}-5.183\}$ & 19 & $0.185(\mathrm{~K}-\mathrm{S})$ \\
\hline \multirow[t]{4}{*}{ C } & Looding & min/100 & Normal $\{\alpha=-8.859$ SD $=0.765\}$ & 14 & $0.341(\mathrm{~K}-\mathrm{S})$ \\
\hline & Travel leaded & $\mathrm{km} \mathrm{h}^{-1}$ & Normal $(\alpha=6.371 \mathrm{SD}=0.269)$ & 14 & $0.201(\mathrm{~K}-\mathrm{S})$ \\
\hline & Unloading & $\min 100$ & Normal $\{\mathrm{a}=9.4 \times 2 \mathrm{SD}=1.004\}$ & 14 & $0.239(\mathrm{~K}-\mathrm{S}\rangle$ \\
\hline & Travel emply & $\mathrm{km} \mathrm{h}^{-1}$ & $\operatorname{Nermal}(a-7.10$ SD $=0.368)$ & 14 & $0,007(\mathrm{~K}-\mathrm{S})$ \\
\hline \multirow[t]{4}{*}{ D } & Losding & $\min 100$ & Nermal $(\alpha-15.93$ SD-0.975) & 8 & $0.058(\mathrm{~K}-\mathrm{S})$ \\
\hline & Travel losded & $\mathrm{km} \mathrm{h}^{-t}$ & Normal $(\alpha-34.6$ SD-2.115) & 8 & $0.067(\mathrm{~K}-5)$ \\
\hline & Unlosding & $\min 100$ & Normal $(\alpha=-18.71$ SD- 1.176$)$ & 8 & 0.163 (K-S) \\
\hline & Travel empty & $\mathrm{km} \mathrm{h}^{-1}$ & $\operatorname{Normal}\{\alpha=35.7 \mathrm{SD}=2.016\}$ & 8 & $0.066(\mathrm{~K}-\mathrm{S})$ \\
\hline
\end{tabular}

$\mathrm{PSH}_{9}=$ Productive system time without delays

TABLE 2 - Elements and parameters of the D-es model.

the study area. As the precise location of all the stump sites was not fixed, the spatial distribution of the load was determined by the Generating random points tool of ArcGIS 9.3-ArcInfo which randomly places a specified number of points within an identified area [ESRI 2009].

As a consequence the volume of each load was determined by a random number generation function according to the distribution resulting by the 105 loads, which were observed during the time and motion study.

For each scenario, a routing analysis was thus carried out to determine the total transportation distance covered by extraction, off-road and on-road transportation to supply all the harvested wood (logs and bundles) to the final terminal. All the routes connecting each load to landings and also the landings to the transshipment sites and the transshipment sites to the terminal were calculated by ArcGIS network analysis [ESRI 2009] according to Djikstra's algorithm, which is implemented for determining a multiple origin-multiple destination or multiple closest facilities [Cavalli 2010].

The network analysis supported thus the definition of the input parameters about the transportation distance for each load according to the 8 scenarios.

Once all the parameters were defined, D-es simulation was launched to perform 15 repetitions for each scenario with a warm-up period of $480 \mathrm{~min}$ and several different sets of random number streams.

On the present work, all the statistical analyses were sorted out using SPSS statistic software [SPSS 2009].

\section{Results}

\subsection{Simulation model parameters}

Table 2 shows the results about the regression models and the distributions and the basic parameters used in the model for the simulations.

The productivity resulting from the composed extraction model, including the regression model of the travel unloaded (TU) and the travel loaded (TL) and the distribution of the hooking and unhooking operations, is reported on Figure 3. This composed model concerning the Step A highlights the effects of the volume and the extraction distance on the effective productivity (calculated on the Productive System Hour without delays - $\left.\mathrm{PSH}_{0}\right)\left(\mathrm{m}^{3} \mathrm{~h}^{-1}\right)$ of the extraction system.

Figure 4 reports the results $\left(\mathrm{m}^{3} \mathrm{~h}-{ }^{1}, \mathrm{PSH}_{0}\right)$ of the regression model of the cut-crossing operation at landing according to the rate of small assortment resulting from the operation respect to the total volume of the load.

\subsection{Influence of the road network extension on the transportation system productivity}

The average output equal to 1.48 truck and trailer per day to the terminal of the 15 replications reported by the D-es model built according to the current state (corresponding to the Scenario B) was considered consistent with the real condition reporting an average of 1.52 truck and trailer per day to the terminal. For this reason the model has been considered reliable and hence it was used for the proposed aims. 


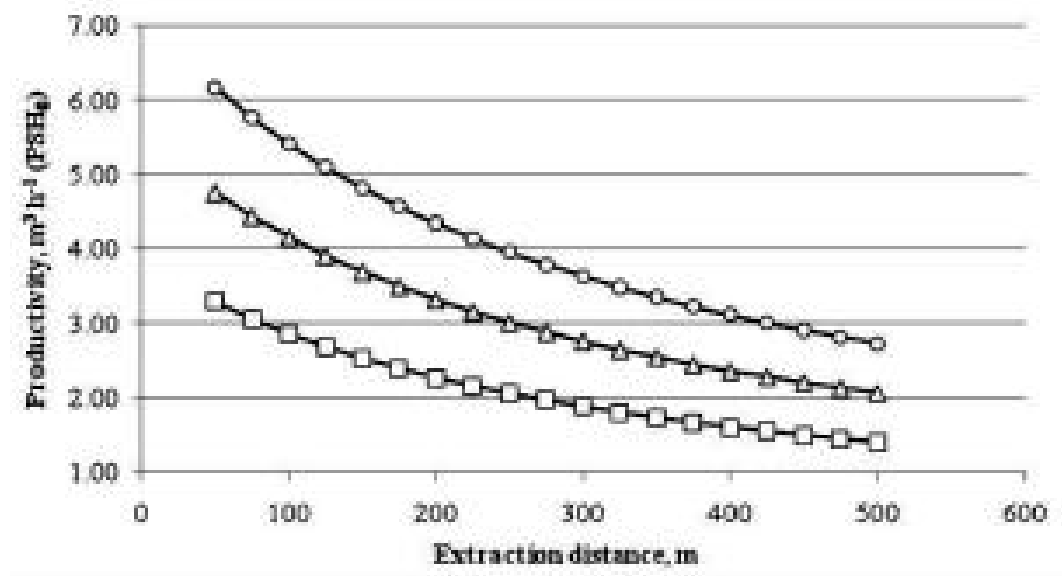

Fig. 3 - Extraction productivity for an average slope of $14 \%$ and three extracted volumes: $1.0 \mathrm{~m}^{3}(-\square-), 1.5 \mathrm{~m}^{3}(-\Delta-)$ and $2.0 \mathrm{~m}^{3}\left(-{ }^{-}\right)$.

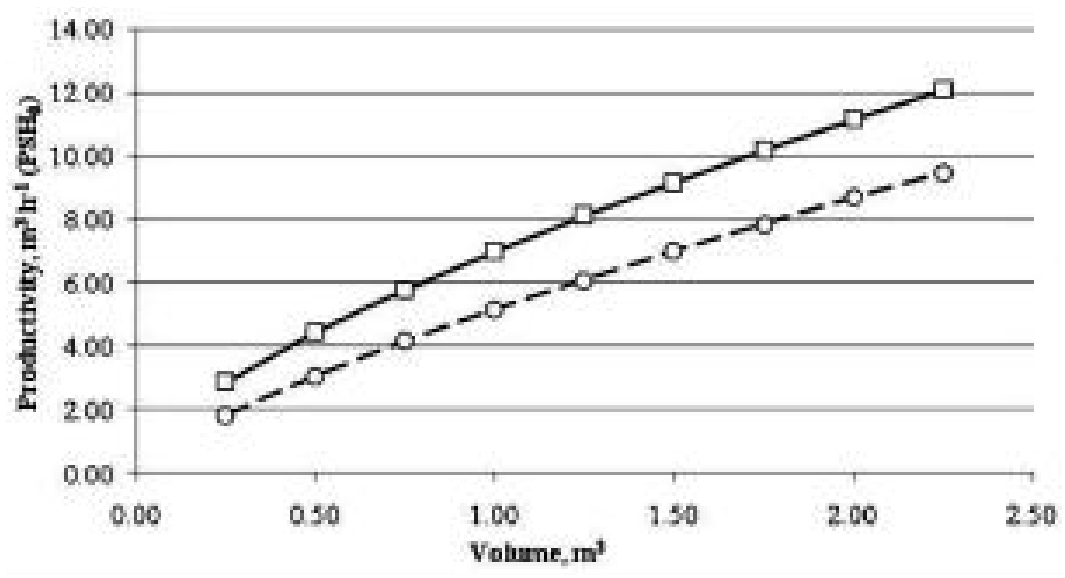

Fig. 4 - Cross-cut productivity with a rate of small assortment higher than $10 \%$ (-○-) and lower than $10 \%(-\square-)$.

The influence of the increment of the forest road density and the extracted volume on the productivity was evaluated by the variance analysis and then by the linear regression analysis. The analysis of the variance reported that the extracted volume does not have a significant effect ( $p$-value 0.067 ) on the productivity of the supply chain, hence the forest road density (DN) was assumed as the main variable influencing the productivity ( $p$-value 0.001 ). For this reason a curve estimation procedure permits to estimate a significant ( $p$-value 0.000 ) regression model at a confidence level of $95 \%$. (Tab. 3) to fit the outputs resulting from the 8 Scenarios (Fig. 5).

From Figure 5 it appears that the increment of the secondary forest road density up to $25-30 \mathrm{~m} \mathrm{ha}^{-1}$ could be considered a significant feature to increase the productivity of the supply chain. As can be seen, the current forest road density (Scenario B) is $14.48 \mathrm{~m}$ $\mathrm{ha}^{-1}$. An increment of the current forest road extension to $20.00 \mathrm{~m} \mathrm{ha}^{-1}$ ( $+38 \%$, corresponding to $62 \mathrm{~m}$ in 11.4 ha) could correspond to a slight increment of the productivity up to $1.8-2.0 \%$. Therefore by the same supposed increment of the forest road network, the sum of the extraction distance (travel unloaded and travel loaded) would decrease for the entire operation of about $18-20 \%$, corresponding to a reduction of 30-34 $\mathrm{km}$ of covered distance.

It should, however, be noted that the curve reported in Figure 5 highlights a slightly positive influence when DN increases over $20-22 \mathrm{~m} \mathrm{ha}^{-1}$.

\begin{tabular}{lllll}
\hline Parameters & Estimation & SD & Statistic, t & P-value \\
Intercept & 22.7773 & 0.196801 & 115.738 & 0.0000 \\
DN Forest road density & -37.8646 & 3.50748 & -10.7954 & 0.0000 \\
\hline REGRFSSION MODEL & Productivity $=\left(22.7773-37.8646 \times \mathrm{DNN}^{-1}\right)^{03}$ & \\
\hline
\end{tabular}

TABLE 3 - Regression model and parameters on the hour productivity $\left(\mathrm{m}^{3} \mathrm{~h}^{-1}\right)$ at terminal. 


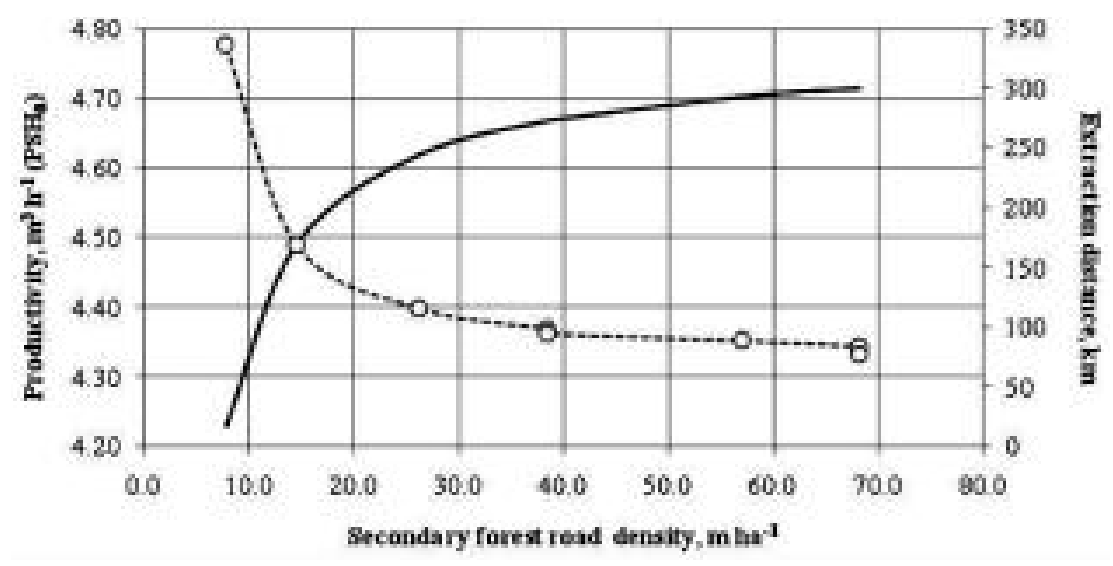

Fig. 5 - Influence of the density of the forest road density on the productivity $(-)$ of the supply chain of wood for firewood production and the corresponding total traveled extraction distance (--○--).

\section{Discussion and conclusion}

Simulation is the process of building a model of a real or proposed system to study the performance of its performance under specific conditions. The analysis of forest operations and wood supply chains has recently been applied in order to analyze discrete and complex real-world situations that could not be solved by analytical operational methods.

The study has presented a first approach of a D-es model integrated with a GIS network analysis to evaluate the influence of the interaction between three main transportation systems occurring during forest operations (extraction, off-road and on-road transportation) on the final productivity of a wood supply chain.

The results indicate that the increment of the forest road network may significantly increase the productivity of the wood supply chain. For the specific investigated condition, the increment of the forest road network showed only a slight increment on the productivity (up to $2 \%$ ). Presumably this correlation depends on the characteristics of the investigated supply chain, which considered a harvesting site characterized by even terrain with an average slope gradient approximately equal to $18 \%$.

According to the general indication reported by Baldini [2008] the current forest road density, evaluated in $14.48 \mathrm{~m} \mathrm{ha}^{-1}$ and corresponding to Scenario B, could be considered a low index for a productive forest. Therefore the increment to $20-22 \mathrm{~m} \mathrm{ha}^{-1}$ could be considered reasonable by taking into account that in average in Italy the forest road network is approximately about $18 \mathrm{~m} \mathrm{ha}^{-1}$ and by considering that in even terrain with a slope gradient of $40 \%$ (higher than the investigated area) forest road density can be approximately to $25-30 \mathrm{~m} \mathrm{ha}^{-1}$ [Hippoliti 2004].

The proposed study highlighted the possibility to integrate the D-es approach with the GIS analysis to support the complex evaluation of the wood supply chains from the stump site to the final processing terminal.

The main limitation of this study was due to the fact that the investigated area represented an operative condition located in medium gentle terrain. Future work should include the analysis of forest productive sites in steep terrain where the forest road density is more complex to evaluate and the extraction transportation network is mainly based on cable systems.

\section{Acknowledgment}

The authors express their appreciation to De Luca Elio forest enterprise from Anzano di Cappella Maggiore, Treviso, Italy, for organizing and performing forest operations analyzed in the study.

\section{References}

Asikainen A., Stampfer K., Talbot B., An evaluation of skyline systems in Norwegians conditions using discreteevent simulation. Proceeding of the International Precisions Forestry Symposium, Stellenbosch University, 2010a, Stellenbosch SA.

Asikainen A., Chipping terminal logistics. Scandinavian Journal of Forest Research, 1998, 13(3), 386-391.

Asikainen A., Discrete-event simulation of mechanized wood-harvesting systems. D.Sc. Thesis, Research notes 38, 1995, University of Joensuu, Faculty of Forestry.

Asikainen A.. Simulation of stump crushing and truck transport of chips. Scandinavian Journal of Forest Research, 2010b, 25(3), 245-250.

Baldini S., Cavalli R., Piegai F., Spinelli R., Di Fulvio F., Fabiano F., Grigolato S., Laudati G., Magagnotti N., Nati C., Picchio R., Prospettive di evoluzione nel settore delle utilizzazioni forestali e dell'approvvigionamento del legname. Proceedings of the Atti del Terzo Congresso Nazionale di Selvicoltura per il miglioramento e la conservazione dei boschi italiani, Firenze, 2009, Accademia Italiana di Scienze Forestali, Vol.2, 717-728, Taormina 16-19 October.

Banks J., Carson J.S., Nelson B.L., Nicol D.M., Discrete event system simulation (4th ed.). Pearson Prentice Hall, 2005, Upper Saddle River NJ. 
Björheden R., Basic time concepts for international comparisons of time study reports. Journal of Forest Engineering, 2001, 2(2): 33-39.

Cavalli R., Grigolato S., Influence of characteristics and extension of a forest road network on the supply cost of forest woodchips. Journal of Forest Research, 2010, 15(3), 202-209.

ESRI, ArcGIS 9.3-ArcInfo. Release 9.3.1., Redland, CA, 2009, Environmental System Research Institute

Hippoliti G., Note pratiche per la realizzazione della viabilità forestale. Compagnia delle Foreste, 2004, Arezzo.

Hogg G., Pulkki R., Ackerman P., Multi-stem mechanized harvesting operation analysis - Application of Arena 9 Dicrete-event simulation software in Zululand, South Africa. Proceeding of the International Precisions Forestry Symposium, Stellenbosch University, 2010, Stellenbosch SA.

Lanner., Witness simulation (release 1.02). Lanner group limited, 2009, Redditch Worc UK.

Law A.M., Kelton W.D., Simulation modeling and analysis. McGraw-Hill, Inc. 1991, New York.

SPSS., SPSS Statistic software. Release 17, SPSS Inc. IBM Company, 2009, Chicago, Illinois.

Stampfer K., Leitner, T., Visser, R., Efficiency and ergonomic benefits of using radio controlled chokers in cable yarding. Croatian Journal of Forest Engineering, 2010, 31(1), 1-8

Talbot B., Suadicani K., Analysis of two simulated in-field chipping and extraction systems in spruce thinning. Biosystems Engineering, 2005, 91(3), 283-292.

Väätäinen K., Liiri H., Röser D., Cost-competitiveness of hardwarders in CTL-logging system in Finland - A discrete event simulation study at the contractor level. Pro- ceeding of the International Precisions Forestry Symposium, Stellenbosch University, 2010, Stellenbosch, SA.

Wang J., LeDoux C., Estimating and validating groundbased timber harvesting production through computer simulation. Forest Science, 2003, 49(1), 64-76.

Ziesak M., Bruchner A.K., Hemm M., Simulation technique for modeling the production chain in forestry. European Journal of Forest Research, 2004, 123: 239-244.

\section{SUMMARY}

In this study a Discrete-event simulation (D-es) has been developed to analyze the wood supply chain for firewood production in a mountain area in North-eastern Italy. The D-es is applied in the modeling of extraction (Full Tree System), processing of roundwood into wood assortments (cross-cut and sorting), offroad and on-road transport.

In order to estimate the productivity functions and parameters, field studies were conducted to gather data about the different operations linked in the model. Also a GIS network analysis was developed to integrate the spatial information onthe covered distance to the D-es model for each of the supposed Scenarios.

The results indicats that an increment of $5 \mathrm{~m} \mathrm{ha}^{-1}$ of the forest road network could significantly increase the productivity of the wood supply chain up to $2 \%$.

Keywords: forest operation, supply chain, firewood, Discrete-event simulation. 